\title{
MAPEAMENTO DAS NOTIFICAÇÕES DE AGRAVOS NO CEREST - MACRO REGIONAL CAMPOS GERAIS, PARANÁ, BRASIL ${ }^{1}$
}

MAPPING DISEASE NOTIFICATIONS IN THE CEREST OF THE REGIONAL MACRO COMPLEX OF THE CAMPOS GERAIS, BRAZIL

\author{
Maria Selena Wendler ${ }^{2}$ \\ Claudia Regina Magnabosco-Martins ${ }^{3}$
}

\section{RESUMO}

Trata-se de uma pesquisa de Iniciação Científica com objetivo de acessar e mapear as notificações dos acidentes de trabalho efetuadas de 2009 a 2015, no CEREST Campos Gerais, no Paraná. Foi realizado o acompanhamento do cotidiano dos trabalhadores do CEREST e a sistematização dos dados do SINAN, analisados por meio de estatística descritiva, da legislação sobre as doenças ocupacionais no país e da literatura de saúde coletiva e do trabalhador. O maior número de notificações ocorreu em 2013, atingindo principalmente homens, da raça branca, com escolaridade até o Ensino Médio e faixa etária de 20 a 49 anos. Acidentes com mutilações foram predominantes com 5.967 notificações, seguidos de 236 acidentes com crianças e adolescentes e 205 acidentes fatais. É necessário aprimorar as notificações e o sistema em que são registradas, sensibilizar e capacitar a rede sentinela a notificar e fazê-lo corretamente, gerando subsídios para ações preventivas em Saúde do Trabalhador.

Palavras-chave: notificações, CEREST; agravos da saúde do trabalhador, saúde do trabalhador, psicologia do trabalho.

\begin{abstract}
Current Scientific Initiation research accesses and maps notifications in labor accidents between 2009 and 2015 at the Workers' Reference Health Center (CEREST) of the Campos Gerais of Paraná, Brazil. The daily monitoring of CEREST workers was carried out and the SINAN data were systematized, analyzed using descriptive statistics, the legislation on occupational diseases in the country and the collective and worker health literature. Highest notification rate occurred in 2013, mainly with white males, aged between 20 and 49 years, up to high school education. Accidents featuring mutilations were predominant, with 5,967 notifications, followed by 236 accidents involving children and adolescents and 205 fatal accidents. Notifications and the registration system should be improved. The sentinel network sensitize and enable to notify and do it correctly, generating subsidies for preventive actions in Workers Health.
\end{abstract}

Keywords: notifications, CEREST, workers' diseases, workers' health, work psychology.

\footnotetext{
1 Pesquisa registrada na Plataforma Brasil, CAAE: 60759416.0.0000.0106, aprovada pelo COMEP/UNICENTRO sob o protocolo 1.864.023.

2 Psicóloga pela Universidade Estadual do Centro-Oeste (UNICENTRO), campus Irati- PR.

3 Psicóloga, Doutora em Saúde Coletiva, Docente do curso de Psicologia da Universidade Estadual do CentroOeste (UNICENTRO), campus Irati- PR.
} 


\section{INTRODUÇÃO}

O campo da Saúde do Trabalhador surgiu em meio a um contexto de transição para a democracia e de diversas transformações sociais e políticas no Brasil. Com a Constituição Federal de 1988 (BRASIL, 1988) a Saúde do Trabalhador foi juridicamente consolidada (GONÇALVES, 2012), de modo a se tornar uma atribuição do Sistema Único de Saúde (SUS) "executar as ações de vigilância sanitária e epidemiológica, bem como as de saúde do trabalhador" (BRASIL, 1988, art. 200).

Mais tarde, o campo da Saúde do Trabalhador foi definido com a publicação da Lei Orgânica da Saúde (LOS), Lei Federal nº 8080, de 19 de setembro de 1990, na qual se estabelece que o campo deve visar "à recuperação e reabilitação da saúde dos trabalhadores submetidos aos riscos e agravos advindos das condições de trabalho" (BRASIL, 1990b, art. 6, $\S 3)$. Em 2012, a Portaria $n^{\circ} 1823$, que institui a Política Nacional da Saúde do Trabalhador e da Trabalhadora - PNSTT (BRASIL, 2012), traz novamente a garantia da universalidade da Saúde do Trabalhador, independentemente do ambiente em que atua e/ou do vínculo empregatício.

Com a Portaria $n^{0} 1679$, de 19 de setembro de 2002, que dispõe sobre a estruturação da Rede Nacional de Atenção Integral à Saúde do Trabalhador (RENAST) no SUS, houve um importante avanço no campo da Saúde do Trabalhador. Ela surgiu com a necessidade de consolidar a PNSTT e instituí-la como uma política de Estado e "tem como principal objetivo integrar a rede de serviços do SUS, voltados à assistência e à vigilância, para o desenvolvimento das ações de Saúde do Trabalhador" (RENAST, 2006, p. 26).

Os Centros Regionais de Referência em Saúde do Trabalhador (CEREST) são, por sua vez, parte da estratégia de efetivação da RENAST e, segundo a Portaria $n^{\circ} 1679$, têm a função de difundir a "cultura especializada subentendida na relação processo de trabalho/ processo saúde/doença, assumindo a função de suporte técnico e científico desse campo do conhecimento" (BRASIL, 2002, p. 7). Portanto, o CEREST não deve se constituir como porta de entrada do sistema, mas sim atuar de forma articulada com os outros serviços do SUS, monitorando suas práticas e a vigilância (BRASIL, 2002). Conforme ressalta o Protocolo sobre Notificações de Acidentes Fatais, Graves e com Crianças e Adolescentes (BRASIL, 2006), as notificações de acidentes de trabalho provocaram a elaboração de modos de atuar em cada CEREST, fornecendo informações das principais características dos acidentes e apontando direções acerca de possíveis intervenções a serem feitas (GONÇALVES, 2012).

No Brasil, em se tratando de acidentes de trabalho, a principal entidade fornecedora de dados a esse respeito é o Instituto Nacional de Seguro Social (INSS). No entanto, as informações fornecidas por esse órgão se referem apenas a dados emitidos por meio da Comunicação de Acidente de Trabalho (CAT) de trabalhadores formais, que contribuem para a Previdência Social (GONÇALVES, 2012).

Com o objetivo de "coletar, transmitir e disseminar dados gerados rotineiramente pelo Sistema de Vigilância Epidemiológica [...] por intermédio de uma rede informatizada, para apoiar o processo de investigação [...] das doenças de notificação compulsória" (BRASIL, 2007, p. 9), foi criado o Sistema Nacional de Informação de Agravos de Notificação - SINAN. Sua implantação ocorreu de forma gradativa a partir de 1993 (BRASIL, 2007) e ele foi regulamentado pela Instrução Normativa $n^{\circ} 2$, de 22 de novembro de 2005, que dá as diretrizes com relação à coleta, ao fluxo e à periodicidade de envio de dados da notificação compulsória de doenças por meio do SINAN.

Os acidentes, como um todo, são agravos que têm grande impacto na morbimortalidade populacional e, por isso, constituem um dos principais problemas da saúde pública no Brasil, 
sendo tratados como prioridade pelo SUS (BRASIL, 2006). A definição de acidente de trabalho é dada pelo Art. 19 da Lei n 8123, de 24 de julho de 1991:

\begin{abstract}
Acidente do trabalho é o que ocorre pelo exercício do trabalho a serviço de empresa ou de empregador doméstico ou pelo exercício do trabalho dos segurados referidos no inciso VII do art. 11 desta Lei, provocando lesão corporal ou perturbação funcional que cause a morte ou a perda ou redução, permanente ou temporária, da capacidade para o trabalho (BRASIL, 1991).
\end{abstract}

São 11 os agravos de notificação compulsória relacionados à saúde do trabalhador que são estabelecidos pela Portaria $\mathrm{n}^{\circ} 204$, de 17 de fevereiro de 2016, e pela Portaria ${ }^{\circ} 205$, de 17 de fevereiro de 2016, sendo eles: 1 . Acidente de trabalho com exposição a material biológico; 2 . Acidente de trabalho: a) grave, b) fatal e em c) crianças e adolescentes; 3. Intoxicação exógena (por substâncias químicas, incluindo agrotóxicos, gases tóxicos e metais pesados); (BRASIL, 2016a); 4. Câncer relacionado ao trabalho; 5. Dermatoses ocupacionais; 6. Lesões por Esforços Repetitivos/Distúrbios Osteomusculares Relacionados ao Trabalho (LER/DORT); 7. Perda Auditiva Induzida por Ruído (PAIR) relacionada ao trabalho; 8. Pneumoconioses relacionadas ao trabalho; 9. Transtornos mentais relacionados ao trabalho (BRASIL, 2016b).

O presente estudo tratará, especificamente, dos Acidentes de Trabalho Graves: Acidentes de Trabalho Fatais, Acidentes de Trabalho com Mutilações (ou Graves) e Acidentes de Trabalho com Crianças e Adolescentes. Os três tipos de agravos são notificados na mesma ficha, pois são considerados graves. Notificar e ter uma base de dados atualizada sobre os agravos relacionados ao trabalho é de suma importância para planejar ações e políticas que visem melhorar as condições de trabalho, dado que tais acidentes são previsíveis e evitáveis (CAMPOS; GURGEL, 2016), além de causarem impacto social na produtividade, na economia e sofrimento psíquico do indivíduo e da família (LACERDA; FERNANDES; NOBRE, 2014a).

Para fins de uma correta notificação dos casos de acidente grave foi publicado, em 2006, pelo Ministério da Saúde, o Protocolo de Notificações de Acidentes de Trabalho Fatais, Graves e com Crianças e Adolescentes, voltado para os profissionais de saúde e toda a rede sentinela de notificação compulsória. O protocolo define o que deve ser classificado como acidente fatal, acidente com mutilação e acidente com crianças e adolescentes. Esses acidentes são definidos da seguinte forma:

Acidente de trabalho fatal é aquele que leva a óbito imediatamente após sua ocorrência ou que venha a ocorrer posteriormente, a qualquer momento, em ambiente hospitalar ou não, desde que a causa básica, intermediária ou imediata da morte seja decorrente do acidente. $[\ldots]$

Acidente de trabalho grave é aquele que acarreta mutilação, física ou funcional, e o que leva à lesão cuja natureza implique em comprometimento extremamente sério, preocupante; que pode ter consequências nefastas ou fatais. [...]

Acidente de trabalho com crianças e adolescentes é aquele que acomete trabalhadores com menos de 18 anos de idade, na data de sua ocorrência (BRASIL, 2006, p. 13).

A rede sentinela citada anteriormente é definida pelo Art. $3^{\circ}$ da Portaria $n^{\circ} 777$, que estabelece o seguinte: "será organizada a partir da porta de entrada no sistema de saúde, estruturada com base nas ações de acolhimento, notificação, atenção integral, envolvendo assistência e vigilância da saúde" (BRASIL, 2004). Ela "é responsável pelo diagnóstico, 
tratamento e notificação, que darão subsídios para ações de prevenção, vigilância e intervenção em Saúde do Trabalhador" (RENAST, 2006, p. 49).

A legislação define dois tipos de acidentes de trabalho: o típico, quando é decorrente da atividade profissional exercida pelo trabalhador; e o acidente de trajeto, quando ocorre no percurso de ida ou volta ao trabalho. Além do acidente decorrente do próprio exercício laboral, há causas externas que também ocasionam acidentes considerados de trabalho, dentre as quais se destaca aqui a violência urbana, pouco visível e reconhecível em sua vinculação imediata com o trabalho. Essa falta de reconhecimento pode gerar problemas e sofrimento ao trabalhador e à sua família (LACERDA et al., 2014a).

De outro lado, o Estatuto da Criança e do Adolescente (ECA), por meio da Lei Federal 8.069, de julho de 1990, define como criança a pessoa com até 12 anos incompletos, e como adolescente, todo aquele entre 12 e 18 anos de idade (BRASIL, 1990a). O Decreto 6.481, de 12 de junho de 2008, que trata das piores formas de trabalho infantil e de sua eliminação, estabelece que adolescentes não podem trabalhar antes dos 14 anos, mas podem fazê-lo como aprendizes entre 14 e 16 anos, desde que o trabalho não esteja entre os citados pelo decreto (BRASIL, 2008). Cabe ressaltar que o ECA é resultado de um processo histórico, permeado por lutas e sofrimento e que, ainda hoje, ainda há muito o que fazer para combater o trabalho infantil. Outra questão acerca da infância e da adolescência é a construção cultural desses termos, uma vez que as crianças eram vistas como "pequenos adultos" e nem sempre se deu importância ao seu desenvolvimento em todos os aspectos cognitivos, físicos e sociais.

Mesmo diante do tempo de existência da Lei Orgânica da Saúde 8.080/90 e do estabelecimento de diversas garantias no que concerne ao campo da Saúde do Trabalhador, de acordo com Dias e Hoefel (2005) o SUS não está preparado para atender as demandas do indivíduo, suas concepções, paradigmas, ações e o papel exercido pelo trabalho, uma vez que não tornou esse processo mais eficiente, pois ainda há muitas subnotificações e problemas com a completude dos dados e o correto preenchimento das fichas, bem como a produção de conhecimento e ações por meio dos dados produzidos.

Ainda que o SINAN seja um sistema de informação eficiente, os “dados sobre acidentes de trabalho continuam a demandar melhores registros, tanto de cobertura, como de qualidade dos dados" (GALDINO; SANTANA; FERRITE, 2012, p. 145). A Portaria ${ }^{\circ}$ 777, de 28 de abril de 2004, traz a necessidade de se dar mais importância a uma "articulação intrassetorial na saúde, baseada na transversalidade das ações de atenção à Saúde do Trabalhador, nos distintos níveis de complexidade do SUS, com destaque para as interfaces com as Vigilâncias Epidemiológica, Sanitária e Ambiental" (BRASIL, 2004).

Tendo em vista os problemas enfrentados na efetivação da PNSST e todas as consequências sociais e subjetivas dos acidentes de trabalho, o campo de Saúde do Trabalhador compreende uma área de conhecimento e práticas que requerem da Psicologia uma ação sobre o trabalho e sobre as bases e processos gerados por meio dos serviços públicos de saúde. Portanto, "cabe à Psicologia contribuir com um olhar para cada sujeito, considerando-o sujeito de um coletivo, resgatar o conhecimento e valorizar a subjetividade dos trabalhadores, para compreender melhor suas práticas de trabalho" (SELLIGMANN-SILVA, 1994; SILVA FILHO, 1997 apud CFP, 2008, p. 28). Bem como "o modo como cada um reage a partir da sua história de vida, de seus valores, das suas crenças, das suas experiências e das suas representações sobre a atividade desenvolvida" (CFP, 2008, p. 28).

Assim, a proposta desta pesquisa surgiu da vinculação da segunda autora com a Comissão Intersetorial de Saúde do Trabalhador e da Trabalhadora (CISTT) de Irati-PR e o 
com o CEREST Campos Gerais, bem como de suas atuações em saúde do trabalhador na região do centro-oeste e centro-sul do Paraná desde 2007, detectando a necessidade de pesquisas sobre os agravos à Saúde do Trabalhador e instigando estudos para dar maior visibilidade ao que acontece no mundo do trabalho regional. Ademais, também visa colaborar para a maior difusão do conhecimento sobre esse campo e a criação de políticas públicas destinadas a aumentar as notificações acerca dos agravos e, consequentemente, evidenciar as ocorrências de acidente e a importância da diminuição da periculosidade no trabalho.

\section{METODOLOGIA}

A pesquisa foi realizada no CEREST Macrorregional Campos Gerais, que tem sede no município de Irati, Paraná, atuando desde 2009 na região que abrange quatro regionais de Saúde (RS) $-4^{\mathrm{a}} \mathrm{RS}$ de Irati, $3^{\mathrm{a}} \mathrm{RS}$ de Ponta Grossa, $6^{\mathrm{a}} \mathrm{RS}$ de União da Vitória e $21^{\mathrm{a}} \mathrm{RS}$ de Telêmaco Borba - e compreende um total 37 municípios, segundo dados da Secretaria de Saúde do Paraná (SESA-PR).

Por meio da coordenação do CEREST, foi contatado o técnico responsável pelas notificações, que é chamado nas Regionais de Saúde (RS) de interlocutor. Ele criou uma base de dados por meio da recuperação de informações apresentadas de forma primária, ou seja, sem organização prévia, apenas por grandes categorias e sem a especificação da identificação nominal da pessoa que teve seu agravo notificado, dado de acesso permitido apenas ao interlocutor.

Como supracitado, o SUS incluiu ao SINAN 11 agravos principais ligados ao trabalho, que integram a lista de principais ocorrências e prioridades no Brasil. Devido à abrangência e à quantidade de informações a serem coletadas e considerando-se o prazo de desenvolvimento da Iniciação Científica, três projetos compuseram o estudo das notificações dos 11 agravos à Saúde do Trabalhador, propostos em um mesmo edital e ano, conformando assim um trio de estudos que mapearam os agravos de saúde do trabalhador na região do CEREST Campos Gerais notificados de 2009 a 2015, período de início das atividades do Centro, até o ano anterior à proposta desta pesquisa. Neste projeto em particular, foram investigadas as notificações quanto aos acidentes de trabalho fatais, acidentes de trabalho com mutilações e acidentes de trabalho com crianças e adolescentes.

Concomitantemente ao processo de coleta de informações, buscou-se entrar em contato com o cotidiano de trabalho do CEREST, conhecendo como trata as notificações e os encaminhamentos dados por meio dessas notificações. Para isso, após o aceite, os funcionários do CEREST assinaram o Termo de Consentimento Livre e Esclarecido (TCLE). Foi utilizado um diário de campo para o registro de observações, questionamentos e impressões das pesquisadoras sobre a experiência que o contato proporcionou.

Nessa direção, o estudo é de cunho misto, quantitativo e qualitativo, na medida em que envolveu diversas formas de acessar as informações que compuseram a compreensão da situação das notificações e dos agravos à saúde do trabalhador na região dos Campos Gerais do Paraná, inclusive no que se refere à relação do pesquisador com os trabalhadores dos serviços que cuidam dessas informações (POUPART, 2008; MINAYO, 2008).

A organização e análise dos dados se deram por meio de sistematização de um banco de dados em planilhas do Excel e de procedimentos estatísticos descritivos dos dados quantitativos. Foram ainda considerados os pressupostos contidos na legislação sobre as doenças ocupacionais no país e na literatura do campo de Saúde do Trabalhador e Saúde Coletiva. 


\section{RESULTADOS}

Como explicitado anteriormente, a ficha de notificação de acidentes graves abrange três agravos: acidente com mutilação, acidente fatal e acidente com crianças e adolescentes. Portanto, para verificar quantas notificações eram referentes a cada agravo, fez-se necessário checar primeiramente a idade do trabalhador (identificando se era criança e/ou adolescente) e se houve óbito, sendo esses dois critérios utilizados para distinguir um agravo do outro. Nesse sentido, optou-se por fazer um texto único que contemplasse as características gerais das notificações estudadas, chegando-se ao número total de 5967 de acidentes com mutilações, seguido de 236 acidentes com crianças e adolescentes e de 205 que resultaram em óbito, conforme se pode visualizar na Tabela 1.

\section{TABELA 1 - SÉRIE HISTÓRICA}

\begin{tabular}{lcccccccc}
\hline \multirow{2}{*}{ Regionais de Saúde } & \multicolumn{9}{c}{ Anos } & \multirow{2}{*}{ Total } \\
\cline { 2 - 8 } & 2009 & 2010 & 2011 & 2012 & 2013 & 2014 & 2015 & \\
\hline 21 RS Telêmaco Borba & 3 & 126 & 275 & 381 & 510 & 148 & 139 & $\mathbf{1 5 8 2}$ \\
\hline 04 RS Irati & 46 & 94 & 203 & 509 & 557 & 533 & 184 & $\mathbf{2 1 2 6}$ \\
\hline 03 RS Ponta Grossa & 38 & 175 & 159 & 236 & 221 & 168 & 201 & $\mathbf{1 1 9 8}$ \\
\hline 06 RS União da Vitória & 60 & 110 & 100 & 201 & 471 & 380 & 180 & $\mathbf{1 5 0 2}$ \\
\hline Total & $\mathbf{1 4 7}$ & $\mathbf{5 0 5}$ & $\mathbf{7 3 7}$ & $\mathbf{1 3 2 7}$ & $\mathbf{1 7 5 9}$ & $\mathbf{1 2 2 9}$ & $\mathbf{7 0 4}$ & $\mathbf{6 4 0 8}$ \\
\hline
\end{tabular}

Fonte: Relatório do SINAN 2009 a 2015, CEREST Campos Gerais-PR.

Segundo a Tabela 1, o ano com maior número de notificações de acidentes graves foi 2013, o segundo 2012 e o terceiro 2014, ocorrendo um aumento das notificações até 2013 e, em seguida, uma decaída. Essa oscilação pode estar ligada a vários fatores, como as ações para incentivar as notificações terem ocorrido mais em um período do que em outro e a presença de subnotificações, isto é, de acidentes que não foram vinculados ao trabalho ou que simplesmente não foram notificados.

TABELA 2 - IDADES DAS PESSOAS COM ACIDENTES NOTIFICADOS

\begin{tabular}{ccccccc}
\hline \multirow{2}{*}{ Idades } & \multicolumn{5}{c}{ Regionais de Saúde } & \multirow{2}{*}{ Total } \\
\cline { 2 - 5 } & Ponta Grossa & Irati & União da Vitória & Telêmaco Borba & $\mathbf{6}$ \\
\hline Crianças (até 12 anos) & $\mathbf{3}$ & $\mathbf{1}$ & $\mathbf{1}$ & $\mathbf{1}$ & $\mathbf{2 3 0}$ \\
\hline Adolescentes (12-18) & $\mathbf{5 3}$ & $\mathbf{7 3}$ & $\mathbf{6 0}$ & $\mathbf{4 4}$ & $\mathbf{3 9 9}$ \\
\hline $18-19$ & 72 & 128 & 111 & 88 & $\mathbf{2 1 2 1}$ \\
\hline $20-29$ & 363 & 708 & 504 & 546 & $\mathbf{1 7 0 5}$ \\
\hline $30-39$ & 325 & 558 & 391 & 278 & $\mathbf{1 1 1 3}$ \\
\hline $40-49$ & 217 & 363 & 255 & 153 & $\mathbf{6 5 9}$ \\
\hline $50-59$ & 133 & 227 & 146 & 29 & $\mathbf{1 5 6}$ \\
\hline $60-69$ & 28 & 60 & 29 & 0 & $\mathbf{1 8}$ \\
\hline $70-79$ & 4 & 8 & 4 & 1 & $\mathbf{1 0 5}$ \\
\hline 80 ou mais & 0 & 0 & 1 & $\mathbf{6 4 0 8}$ \\
\hline Total & $\mathbf{1 1 9 8}$ & $\mathbf{2 1 2 6}$ & $\mathbf{1 5 0 2}$ & & $\mathbf{1 5 2}$ \\
\hline
\end{tabular}

Fonte: Relatório do SINAN 2009 a 2015, CEREST Campos Gerais-PR. 
No que tange à idade, os acidentes afetaram principalmente adultos jovens de 20 a 29 anos (33,10\%), mas também ganham destaque as faixas etárias de 30 a $39(26,60 \%)$ e 40 a 49 anos (17,37\%), que juntas perfazem 77,07\%, demonstrando que os acidentes de trabalho ocorreram predominantemente na faixa etária mais produtiva, tal como aparecem em outros estudos brasileiros (IWAMOTO et al., 2011; GONÇALVES, 2012; CARDOSO et al., 2016).

A percentagem de agravos que atingiu crianças pode ser considerada pequena em relação ao geral (0,09\%), o que não elimina a possibilidade de subnotificação. Em compensação, no que se refere a adolescentes, o índice é bem maior (3,59\%). Tais dados não podem ser ignorados, pois indicam a existência de casos de trabalho infantil e adolescente e que há muito a ser conquistado para que essa prática seja extinta.

Os acidentes atingiram predominantemente homens (84,35\%), mas o número de mulheres também é significativo (15,65\%). A predominância de acidentes de trabalho na população masculina também é encontrada em outros estudos (SANTANA et al., 2013; IWAMOTO et al., 2011; GONÇALVES, 2012; CARDOSO et al., 2016). Entre as mulheres que sofreram acidente de trabalho grave, foram notificados oito casos de gravidez, sendo três $(0,05 \%)$ no $1^{\circ}$ semestre e cinco $(0,08 \%)$ no $2^{\circ}$ semestre. Os 34 casos marcados como ignorados ou em branco chamam a atenção $(0,53 \%)$, podendo demonstrar uma incompletude nos dados ou que não houve tentativa de identificar a existência de gravidez ou não.

No que diz respeito à raça, a maioria dos trabalhadores afetados foram identificados como brancos $(87,87 \%)$, seguidos de pardos $(8,94 \%)$, negros $(1,84 \%)$, amarelos $(0,25 \%)$ e indígenas (0,03\%), algo parecido com um estudo realizado por Scussiato et al. (2013) no Paraná. A predominância de notificações de agravos em indivíduos brancos pode estar relacionada às características da região dos Campos Gerais, que tem boa parte de sua população composta por imigrantes europeus. Os dados do censo do IBGE (2010) mostram que a população do Paraná estava estimada em 10.444.526, dos quais 7.344.122 se caracterizaram como brancos; 2.620 .378 como pardos; 330.830 como negros; 123.205 como amarelos e 25.915 como indígenas (IBGE, 2010). Isso explicaria a predominância dos agravos na população branca e parda em comparação às demais raças, contudo, não significa que não haja subnotificações nos acidentes referentes à população negra, amarela e indígena, por exemplo.

TABELA 3 - ESCOLARIDADE DAS PESSOAS COM ACIDENTES NOTIFICADOS

\begin{tabular}{|c|c|c|c|c|c|}
\hline \multirow{2}{*}{ Escolaridade } & \multicolumn{4}{|c|}{ Regionais de Saúde } & \multirow{2}{*}{ Total } \\
\hline & Ponta Grossa & Irati & União da Vitória & Telêmaco Borba & \\
\hline Ign/Branco & 166 & 31 & 148 & 488 & 833 \\
\hline Analfabeto & 10 & 10 & 6 & 28 & 54 \\
\hline $\begin{array}{l}1^{\mathrm{a}} \text { a } 4^{\mathrm{a}} / 5 \text { a } 8^{\mathrm{a}} \text { série incompleta } \\
\text { do Ensino Fundamental }\end{array}$ & 342 & 914 & 504 & 345 & 2105 \\
\hline $\begin{array}{l}4^{\mathrm{a}} \text { série completa do Ensino } \\
\text { Fundamental }\end{array}$ & 96 & 228 & 139 & 104 & 567 \\
\hline Ensino Fundamental completo & 114 & 331 & 157 & 120 & 722 \\
\hline Ensino Médio incompleto & 121 & 204 & 163 & 140 & 628 \\
\hline Ensino Médio completo & 317 & 349 & 337 & 326 & 1329 \\
\hline Educação Superior incompleta & 12 & 17 & 28 & 11 & 68 \\
\hline Educação Superior completa & 19 & 42 & 18 & 18 & 97 \\
\hline Não se aplica & 1 & 0 & 2 & 2 & 5 \\
\hline Total & 1198 & 2126 & 1502 & 1582 & 6408 \\
\hline
\end{tabular}

Fonte: Relatório do SINAN 2009 a 2015, CEREST Campos Gerais-PR. 
Quanto ao grau de escolaridade, pode-se observar, na Tabela 3, que grande parte dos trabalhadores que sofreram acidente de trabalho grave não têm ensino superior ou não concluíram os ensinos Fundamental e Médio. Ganha destaque o fato de a maioria deles terem no máximo Ensino Médio completo, diminuindo consideravelmente o número de acidentes em trabalhadores com Ensino Superior incompleto ou completo, o que mostra o quanto os acidentes de trabalho estão relacionados a questões sociais e econômicas.

Tais resultados coincidem com aqueles obtidos por Scussiato et al. (2013), Cavalcante et al.(2015), Campos e Gurgel (2016), em que os acidentes afetaram principalmente pessoas com Ensino Médio completo e $5^{\mathrm{a}}$ a $8^{\mathrm{a}}$ série incompleta do Ensino Fundamental. Os casos marcados como ignorados ou em branco também têm número significativo (13\%). O não preenchimento também foi encontrado nos estudos realizados por Gonçalves (2012), Cavalcante et al. (2015), Campos e Gurgel (2016) e Cardoso et al. (2016). Essa questão indica um inadequado preenchimento das fichas, o desconhecimento de partes dela e de sua importância para as ações em saúde pública (GONÇALVES, 2012) ou mesmo a falta de tempo para seu preenchimento por parte dos profissionais de saúde, indicando a sobrecarga de trabalho em seu cotidiano.

A Tabela 4 apresenta os 10 municípios com maior número de notificações no CEREST Campos Gerais, predominando Telêmaco Borba (20,16\%), Irati (19,72\%) e São Mateus do $\operatorname{Sul}(9,33 \%)$.

TABELA 4 - MUNICÍPIOS COM MAIOR NÚMERO DE NOTIFICAÇÕES

\begin{tabular}{lcccccc}
\hline \multirow{2}{*}{ Municípios } & \multicolumn{5}{c}{ Regionais de Saúde } & \multirow{2}{*}{ Total } \\
\cline { 2 - 5 } & Ponta Grossa & Irati & União da Vitória & Telêmaco Borba & $\mathbf{1 2 9 2}$ \\
\hline Telêmaco Borba & 0 & 0 & 0 & 0 & 1292 & $\mathbf{1 2 6 4}$ \\
\hline Irati & 0 & 1264 & 0 & 0 & $\mathbf{5 9 8}$ \\
\hline São Mateus do Sul & 0 & 0 & 598 & 0 & $\mathbf{3 8 8}$ \\
\hline Ponta Grossa & 388 & 0 & 0 & 341 & 0 & $\mathbf{3 4 1}$ \\
\hline União da Vitória & 0 & 0 & 0 & 0 & $\mathbf{3 1 7}$ \\
\hline Imbituva & 0 & 317 & 0 & 0 & $\mathbf{2 5 4}$ \\
\hline Arapoti & 254 & 0 & 0 & 0 & $\mathbf{1 6 5}$ \\
\hline Bituruna & 0 & 0 & 0 & 0 & 0 & $\mathbf{1 4 5}$ \\
\hline Jaguariaíva & 145 & 134 & 0 & $\mathbf{1 5 8 2}$ & $\mathbf{6 4 0 8}$ \\
\hline Mallet & 0 & $\mathbf{2 1 2 6}$ & $\mathbf{1 5 0 2}$ & 0 \\
\hline Total geral & $\mathbf{1 1 9 8}$ & & & 0 & $\mathbf{1 3 4}$ \\
\hline
\end{tabular}

Fonte: Relatório do SINAN 2009 a 2015, CEREST Campos Gerais-PR.

Mesmo sendo o maior munícipio da região, com 311.611 habitantes (IBGE, 2010), Ponta Grossa não apresenta número de notificações condizentes, correspondendo a $6,05 \%$ do total, o que pode indicar subnotificações, visto que tem um dos principais polos industriais e agrícolas da região.

Referente ao município de residência, há mais notificações nos municípios de Telêmaco Borba (18,05\%), Irati (16,82\%) e São Mateus do Sul (8,97\%). No que concerne ao município do acidente, os que tiveram maior incidência de agravos são Telêmaco Borba (18,98\%), Irati $(17,41 \%)$ e São Mateus do Sul (9,11\%). Por fim, os dados coincidem com os encontrados acerca do munícipio de atendimento, no qual os municípios com maior número de agravos são os três citados. 
Sobre a zona de residência, a maioria dos atingidos reside na área urbana (64,84\%), havendo um número significativo na área rural $(18,29 \%)$ e na zona periurbana $(15,40 \%)$, respostas também encontradas por Gonçalves (2012).

\section{TABELA 5 - LOCAIS DE OCORRÊNCIA DOS ACIDENTES}

\begin{tabular}{|c|c|c|c|c|c|}
\hline \multirow{2}{*}{ Local } & \multicolumn{4}{|c|}{ Regionais de Saúde } & \multirow{2}{*}{ Total } \\
\hline & Ponta Grossa & Irati & União da Vitória & Telêmaco Borba & \\
\hline Instalações contratante & 786 & 1475 & 961 & 1153 & 4375 \\
\hline Via pública & 217 & 329 & 154 & 227 & 927 \\
\hline Instalações de terceiros & 92 & 155 & 148 & 151 & 546 \\
\hline Domicílio próprio & 63 & 157 & 201 & 42 & 463 \\
\hline Ign/Branco & 40 & 10 & 38 & 9 & 97 \\
\hline Total & 1198 & 2126 & 1502 & 1582 & 6408 \\
\hline
\end{tabular}

Fonte: Relatório do SINAN 2009 a 2015, CEREST Campos Gerais-PR.

Os locais do acidente foram predominantemente as instalações do contratante $(68,27 \%)$; vias públicas $(14,47 \%)$ e instalações de terceiros $(8,52 \%)$, dados correspondentes aos de Gonçalves (2012), Scussiato et al. (2013) e Cardoso et al. (2016). Os acidentes em vias públicas podem ser resultado da violência urbana, mais dificilmente vinculados ao trabalho, se comparados aos acidentes típicos e ocorridos nas instalações do contratante (LACERDA et al., 2014a).

Os acidentes típicos são aqueles que resultam da atividade profissional desempenhada, e os acidentes de trajeto, aqueles que ocorrem no percurso de ida ou volta ao trabalho. Os agravos analisados neste estudo foram os típicos $(86,69 \%)$ e, em menor número, os de trajeto (11,28\%), dados compatíveis com investigações em Belo Horizonte (GONÇALVES, 2012), Paraná (SCUSSIATO et al., 2013), Salvador (LACERDA et al., 2014a), São José do Rio Preto (CARDOSO et al., 2016) e Rio Grande do Norte (CAVALCANTE et al., 2015).

\section{TABELA 6 - UNIDADES DE SAÚDE NOTIFICADORAS}

\begin{tabular}{|c|c|c|c|c|c|}
\hline \multirow{2}{*}{ Unidades } & \multicolumn{4}{|c|}{ Regionais de Saúde } & \multirow{2}{*}{ Total } \\
\hline & Ponta Grossa & Irati & União da Vitória & Telêmaco Borba & \\
\hline Hospital & 877 & 1015 & 374 & 376 & 2642 \\
\hline Centro de Saúde & 158 & 787 & 152 & 250 & 1347 \\
\hline $\begin{array}{l}\text { Departamento Municipal de } \\
\text { Saúde e Assistência Social/ } \\
\text { SMS }\end{array}$ & 2 & 50 & 8 & 922 & 982 \\
\hline $\begin{array}{l}\text { Ambulatório/ Clínica } \\
\text { Médica/ Centro Médico }\end{array}$ & 0 & 2 & 857 & 0 & 859 \\
\hline Pronto Atendimento & 33 & 76 & 33 & 0 & 142 \\
\hline UBS/Posto de Saúde & 4 & 79 & 25 & 30 & 138 \\
\hline $\begin{array}{l}\text { Serviço de Vigilância } \\
\text { Epidemiológica/Setor de } \\
\text { Vigilância em Saúde }\end{array}$ & 92 & 0 & 0 & 0 & 92 \\
\hline Centro Social Rural & 8 & 28 & 51 & 0 & 87 \\
\hline $\begin{array}{l}\text { ESF/Unidade de Saúde da } \\
\text { Família }\end{array}$ & 9 & 60 & 1 & 4 & 74 \\
\hline
\end{tabular}




\begin{tabular}{lccccc}
\hline Clínica de Fisioterapia & 0 & 29 & 0 & 0 & $\mathbf{2 9}$ \\
\hline $\begin{array}{l}\text { Centro de Atenção Integral } \\
\text { a Mulher e a Criança/ } \\
\text { Unidade Materno Infantil }\end{array}$ & 8 & 0 & 1 & 0 & $\mathbf{9}$ \\
\hline $\begin{array}{l}\text { SAE Serviço de Assistência } \\
\text { Especializada }\end{array}$ & 7 & 0 & 0 & 0 & $\mathbf{7}$ \\
\hline Total & $\mathbf{1 1 9 8}$ & $\mathbf{2 1 2 6}$ & $\mathbf{1 5 0 2}$ & $\mathbf{1 5 8 2}$ & $\mathbf{6 4 0 8}$ \\
\hline
\end{tabular}

Fonte: Relatório do SINAN 2009 a 2015, CEREST Campos Gerais-PR.

As unidades de saúde foram agrupadas na Tabela 6 para facilitar a visualização. Nela é possível verificar que as unidades que mais notificaram foram hospitais $(41,23 \%)$; centros de saúde (21,02\%); departamentos de saúde e assistência (14,95\%) e ambulatórios, clínicas médicas e centros médicos $(13,40 \%)$. Ganham destaque as notificações feitas pelos departamentos e secretarias municipais de saúde, pois embora tenham uma nomenclatura administrativa, os locais de pronto atendimento ou de porta aberta são comumente assim denominados nos munícipios ou em alguns casos em que os dois serviços - administrativos e assistenciais ocorrem no mesmo lugar.

\section{TABELA 7 - OCUPAÇÕES AGRUPADAS DE ACORDO COM OS GRANDES GRUPOS OCUPACIONAIS - CBO}

\begin{tabular}{|c|c|c|c|c|c|}
\hline \multirow{2}{*}{ Ocupações } & \multicolumn{4}{|c|}{ Regionais de Saúde } & \multirow{2}{*}{ Total } \\
\hline & Ponta Grossa & Irati & União da Vitória & Telêmaco Borba & \\
\hline $\begin{array}{l}7 \text { Trabalhadores da produção de } \\
\text { bens e serviços industriais }\end{array}$ & 555 & 1025 & 603 & 941 & 3124 \\
\hline $\begin{array}{l}6 \text { Trabalhadores agropecuários, } \\
\text { florestais e da pesca }\end{array}$ & 220 & 332 & 295 & 161 & 1008 \\
\hline $\begin{array}{l}5 \text { Trabalhadores dos serviços, } \\
\text { vendedores do comércio em lojas } \\
\text { e mercados }\end{array}$ & 153 & 152 & 148 & 128 & 581 \\
\hline $\begin{array}{l}9 \text { Trabalhadores em serviços de } \\
\text { reparação e manutenção }\end{array}$ & 93 & 183 & 128 & 115 & 519 \\
\hline $\begin{array}{l}8 \text { Trabalhadores da produção de } \\
\text { bens e serviços industriais }\end{array}$ & 47 & 166 & 190 & 80 & 483 \\
\hline $\begin{array}{l}4 \text { Trabalhadores de serviços } \\
\text { administrativos }\end{array}$ & 68 & 119 & 71 & 53 & 311 \\
\hline 3 Técnicos de nível médio & 33 & 71 & 37 & 61 & 202 \\
\hline $\begin{array}{l}2 \text { Profissionais das ciências e das } \\
\text { artes }\end{array}$ & 14 & 34 & 15 & 30 & 93 \\
\hline $\begin{array}{l}1 \text { Membros superiores do poder } \\
\text { público, dirigentes de organiza- } \\
\text { ções de interesse público e de } \\
\text { empresas, gerentes }\end{array}$ & 12 & 27 & 14 & 10 & 63 \\
\hline $\begin{array}{l}0 \text { Membros das forças armadas, } \\
\text { policiais e bombeiros militares }\end{array}$ & 2 & 13 & 1 & 3 & 19 \\
\hline Total & 1197 & 2122 & 1502 & 1582 & 6403 \\
\hline
\end{tabular}

Fonte: Relatório do SINAN 2009 a 2015, CEREST, Campos Gerais-PR. 
Na Tabela 7 são apresentadas as ocupações organizadas em grandes grupos, de acordo com a classificação do CBO (2002) para facilitar a visualização. Aquelas em que houve maior número de notificações foram do setor de produção de bens e serviços industriais $(48,79 \%)$; do setor agropecuário, florestal e de pesca $(15,74 \%)$ e os setores de serviços, vendedores de comércio $(9,07 \%)$ e dos serviços em manutenção e reparação $(8,10 \%)$. A predominância de acidentes nos grupos ocupacionais 7 e 6 (conforme a Tabela 7) correspondem a achados de outros estudos no Brasil (CAMPOS; GURGEL, 2016; CAVALCANTE et al., 2015; SCUSSIATO et al., 2013). Dentre as profissões mais afetadas pelos acidentes de trabalho estão: alimentador de linha de produção $(13,15 \%)$, pedreiro $(5,65 \%)$, servente de obras $(4,48 \%)$, trabalhador agropecuário em geral $(4,38 \%)$, motorista de caminhão $(3,40 \%)$ e trabalhador volante da agricultura $(3,32 \%)$.

A prevalência de acidentes nos setores industrial e agrícola estava diretamente atrelada à zona de residência. Os acidentes ocorreram principalmente na área urbana, onde estão os principais polos industriais, e na área rural, onde se dá o cultivo agrícola. Ressalta-se uma inconsistência no total dos dados retirados do SINAN na Tabela 7, possivelmente provocada por erros no preenchimento das fichas.

A maioria dos trabalhadores $(76,23 \%)$ não trabalhava em empresa terceirizada, seguido por ignorado ou em branco (16,54\%), sendo que apenas 3,84\% trabalhavam nesse tipo de empresa, condizente com os achados de Gonçalves (2012).

TABELA 8 - SITUAÇÃO NO MERCADO DE TRABALHO DAS PESSOAS ACIDENTADAS

\begin{tabular}{|c|c|c|c|c|c|}
\hline \multirow{2}{*}{$\begin{array}{c}\text { Situação no mercado de } \\
\text { trabalho }\end{array}$} & \multicolumn{4}{|c|}{ Regionais de Saúde } & \multirow{2}{*}{ Total } \\
\hline & Ponta Grossa & Irati & União da Vitória & Telêmaco Borba & \\
\hline Empregado registrado & 783 & 1471 & 925 & 1313 & 4492 \\
\hline Autônomo & 175 & 309 & 328 & 88 & 900 \\
\hline Empregado não registrado & 140 & 192 & 156 & 101 & 589 \\
\hline Ign./Branco & 39 & 10 & 23 & 30 & 102 \\
\hline Serv. Púb. Estatutário & 18 & 49 & 13 & 13 & 93 \\
\hline Trab. temporário & 9 & 32 & 18 & 11 & 70 \\
\hline Outros & 10 & 20 & 16 & 4 & 50 \\
\hline Aposentado & 3 & 16 & 8 & 5 & 32 \\
\hline Serv. Púb. Celetista & 10 & 11 & 1 & 3 & 25 \\
\hline Empregador & 3 & 7 & 6 & 8 & 24 \\
\hline Trab. avulso & 6 & 4 & 4 & 4 & 18 \\
\hline Desempregado & 1 & 4 & 3 & 1 & 9 \\
\hline Cooperativado & 1 & 1 & 1 & 1 & 4 \\
\hline Total & 1198 & 2126 & 1502 & 1582 & 6408 \\
\hline
\end{tabular}

Fonte: Relatório do SINAN 2009 a 2015 CEREST Campos Gerais-PR.

Quanto à situação no mercado de trabalho, o que sobressai são empregados registrados (70,10\%); trabalhadores autônomos (14,04\%) e empregados não registrados (9,19\%), prevalência também encontrada por outros autores (GONÇALVES, 2012; CAMPOS; GURGEL, 2016; CAVALCANTE et al., 2015; CARDOSO et al., 2015; SCUSSIATO et al., 2013). O Comunicado de Acidente de Trabalho (CAT) não foi emitido na maior parte dos casos (44,37\%), sendo que casos ignorados ou em branco representam 32,32\%, achados compatíveis com os já encontrados por Campos e Gurgel (2016). O CAT, ao ser emitido para o INSS, garante aos empregados registrados os benefícios previstos na Lei 8.123, de 24 de julho de 
1991. Apenas $21,35 \%$ dos casos deste estudo tiveram o CAT emitido. Houve poucos casos em que trabalhadores relataram que seus colegas de trabalho haviam sido atingidos $(4,27 \%)$ no mesmo acidente, situação que permite pensar na periculosidade do local e das condições de trabalho por eles compartilhados.

A Tabela 9 traz o código da causa do acidente. Nela estão apenas os 10 de maior ocorrência.

\section{TABELA 9 - CÓDIGOS DO CID 10 DE MAIOR OCORRÊNCIA QUANTO A CAUSA DO ACIDENTE}

\begin{tabular}{|c|c|c|c|c|c|}
\hline \multirow[b]{2}{*}{ Códigos das causas do acidente } & \multicolumn{4}{|c|}{ Regionais de Saúde } & \multirow[b]{2}{*}{ Total } \\
\hline & $\begin{array}{l}\text { Ponta } \\
\text { Grossa }\end{array}$ & Irati & $\begin{array}{l}\text { União da } \\
\text { Vitória }\end{array}$ & $\begin{array}{l}\text { Telêmaco } \\
\text { Borba }\end{array}$ & \\
\hline Y96 Acidente de trabalho grave & 200 & 61 & 74 & 415 & 750 \\
\hline $\begin{array}{l}\text { W31 Contato com outras maquinas e } \\
\text { com as não especificadas }\end{array}$ & 105 & 70 & 172 & 185 & 532 \\
\hline $\begin{array}{l}\text { W20 Impacto causado por objeto } \\
\text { lançado, projetado ou em queda }\end{array}$ & 37 & 96 & 118 & 162 & 413 \\
\hline $\begin{array}{l}\text { W23 Apertado, colhido, comprimido } \\
\text { ou esmagado dentro de ou entre objetos }\end{array}$ & 51 & 99 & 147 & 82 & 379 \\
\hline $\begin{array}{l}\text { W29 Contato com outros utensílios } \\
\text { manuais e aparelhos domésticos } \\
\text { equipados com motor }\end{array}$ & 83 & 76 & 66 & 31 & 256 \\
\hline $\begin{array}{l}\text { W27 Contato com ferramentas manuais } \\
\text { sem motor }\end{array}$ & 21 & 20 & 58 & 66 & 165 \\
\hline $\begin{array}{l}\text { W01 Queda no mesmo nível por } \\
\text { escorregão, tropeção ou passos em } \\
\text { falsos [traspes] }\end{array}$ & 13 & 14 & 30 & 97 & 154 \\
\hline $\begin{array}{l}\text { W44 Penetração de corpo estranho no } \\
\text { ou através de olho ou orifício natural }\end{array}$ & 0 & 23 & 50 & 33 & 106 \\
\hline $\begin{array}{l}\text { W13 Queda de ou para fora de } \\
\text { edifícios ou outras estruturas }\end{array}$ & 39 & 4 & 18 & 40 & 101 \\
\hline $\begin{array}{l}\text { W26 Contato com faca, espada e } \\
\text { punhal }\end{array}$ & 5 & 21 & 45 & 17 & 88 \\
\hline Total geral & 895 & 729 & 1166 & 1473 & 4263 \\
\hline
\end{tabular}

Fonte: Relatório do SINAN 2009 a 2015, CEREST Campos Gerais-PR.

É perceptível que grande parte dos acidentes foi notificada com o código Y96 como causa do acidente $(11,70 \%)$, o que é um erro de preenchimento, já que ele se refere ao agravo e não à causa do acidente. Dito isso, as causas mais citadas são o contato com outras máquinas $(8,30 \%)$; impacto causado por objeto lançado, projetado ou em queda $(6,44 \%)$ e ser apertado, colhido, comprimido ou esmagado dentro de ou entre objetos $(5,91 \%)$. Mesmo que na tabela sejam expressos os códigos de maior ocorrência no estudo, ainda resta uma incoerência no total geral apresentado, que tem um déficit de 2.145 dados, isto é, o total deveria ser 6.408, mas na tabela é de 4.263. 
TABELA 10 - PARTES DO CORPO ATINGIDAS NO ACIDENTE

\begin{tabular}{|c|c|c|c|c|c|}
\hline \multirow{2}{*}{$\begin{array}{l}\text { Parte do corpo } \\
\text { atingida }\end{array}$} & \multicolumn{4}{|c|}{ Regionais de Saúde } & \multirow{2}{*}{ Tota } \\
\hline & Ponta Grossa & Irati & União da Vitória & Telêmaco Borba & \\
\hline Mão & 429 & 809 & 649 & 565 & 2452 \\
\hline Membro superior & 170 & 340 & 160 & 209 & 879 \\
\hline Membro inferior & 169 & 282 & 170 & 188 & 809 \\
\hline Cabeça & 124 & 209 & 140 & 137 & 610 \\
\hline Pé & 66 & 148 & 125 & 145 & 484 \\
\hline Olho & 32 & 105 & 118 & 80 & 335 \\
\hline Outro & 37 & 85 & 36 & 132 & 290 \\
\hline Tórax & 45 & 73 & 60 & 56 & 234 \\
\hline Todo o corpo & 57 & 24 & 11 & 18 & 110 \\
\hline Abdome & 24 & 33 & 12 & 29 & 98 \\
\hline Pescoço & 18 & 14 & 10 & 19 & 61 \\
\hline Ign./Branco & 27 & 4 & 11 & 4 & 46 \\
\hline Total & 1198 & 2126 & 1502 & 1582 & 6408 \\
\hline
\end{tabular}

Fonte: Relatório do SINAN 2009 a 2015, CEREST Campos Gerais-PR.

As partes do corpo mais atingidas são os órgãos ou as áreas da parte superior, sendo que $38,26 \%$ dos acidentes atingiram as mãos; $13,72 \%$, os membros superiores; $12,62 \%$, os membros inferiores, e 9,52\%, a cabeça. Tais resultados são similares aos achados de Scussiato et al. (2010), Campos e Gurgel (2016), Cardoso et al. (2016) e Cavalcante et al. (2015).

\section{TABELA 11 - DIAGNÓSTICOS DAS LESÕES PROVOCADAS PELO ACIDENTE}

\begin{tabular}{lcccccc}
\hline \multicolumn{1}{c}{ Diagnóstico da lesão } & \multicolumn{5}{c}{ Regionais de Saúde } & \multirow{2}{*}{ Total } \\
\cline { 2 - 5 } & Ponta Grossa & Irati & União da Vitória & Telêmaco Borba & \\
\hline $\begin{array}{l}\text { S610 Ferimento de dedo(s) sem } \\
\text { lesão da unha }\end{array}$ & 37 & 243 & 104 & 171 & $\mathbf{5 5 5}$ \\
\hline $\begin{array}{l}\text { S619 Ferimento do punho e da } \\
\text { mão, parte não especificada }\end{array}$ & 11 & 150 & 20 & 97 & $\mathbf{2 7 8}$ \\
\hline S61 Ferimento do punho e da mão & 19 & 32 & 170 & 14 & $\mathbf{2 3 5}$ \\
\hline $\begin{array}{l}\text { S611 Ferimento de dedo(s) com } \\
\text { lesão da unha }\end{array}$ & 26 & 40 & 54 & 16 & $\mathbf{1 3 6}$ \\
\hline $\begin{array}{l}\text { S681 Amputação traumática de } \\
\text { outro dedo apenas (completa) } \\
\text { (parcial) }\end{array}$ & 22 & 53 & 17 & 39 & $\mathbf{1 3 1}$ \\
\hline $\begin{array}{l}\text { S913 Ferimento de outras partes } \\
\text { do pé }\end{array}$ & 5 & 70 & 18 & 29 & $\mathbf{1 2 2}$ \\
\hline $\begin{array}{l}\text { S819 Ferimento da perna, parte } \\
\text { não especificada }\end{array}$ & 7 & 64 & 5 & 35 & $\mathbf{1 1 1}$ \\
\hline S626 Fratura de outros dedos & 19 & 44 & 7 & 40 & $\mathbf{1 1 0}$ \\
\hline $\begin{array}{l}\text { S68 Amputação traumática ao } \\
\text { nível do punho e da mão }\end{array}$ & 57 & 12 & 25 & 13 & $\mathbf{1 0 7}$ \\
\hline Y96 Acidente de trabalho grave & 55 & 9 & 12 & 19 & $\mathbf{9 5}$ \\
\hline Total geral & $\mathbf{1 1 9 2}$ & $\mathbf{2 1 2 3}$ & $\mathbf{1 4 9 3}$ & $\mathbf{1 5 7 9}$ & $\mathbf{6 3 8 7}$ \\
\hline
\end{tabular}

Fonte: Relatório do SINAN 2009 a 2015, CEREST Campos Gerais-PR. 
Concernente aos diagnósticos das lesões, os mais recorrentes foram ferimento de dedo(s) sem lesão da unha $(8,66 \%)$; ferimento do punho e da mão, parte não especificada $(4,34 \%)$, e ferimento do punho e da mão $(3,67 \%)$.

A Tabela 11 apresenta somente os 10 diagnósticos mais recorrentes, sendo que o código Y96 aparece igualmente de forma incorreta, ocorrendo novamente uma incongruência nos dados na tabela integral colhida no SINAN, na qual o total aparece com 6.387 notificações em vez de 6.408 .

TABELA 12 - REGIME DE TRATAMENTO A PESSOA ACIDENTADA

\begin{tabular}{|c|c|c|c|c|c|}
\hline \multirow{2}{*}{ Regime de tratamento } & \multicolumn{4}{|c|}{ Regionais de Saúde } & \multirow{2}{*}{ Total } \\
\hline & Ponta Grossa & Irati & União da Vitória & Telêmaco Borba & \\
\hline Ambulatorial & 379 & 1527 & 1155 & 865 & 3926 \\
\hline Hospitalar & 671 & 472 & 245 & 459 & 1847 \\
\hline Ign./Branco & 115 & 20 & 40 & 217 & 392 \\
\hline Ambos & 33 & 107 & 62 & 41 & 243 \\
\hline Total & 1198 & 2126 & 1502 & 1582 & 6408 \\
\hline
\end{tabular}

Fonte: Relatório do SINAN 2009 a 2015, CEREST Campos Gerais-PR.

Em 96,28\% dos casos ocorreu atendimento médico e em 2,75\% não, número consideravelmente baixo. Ignorados ou em branco somaram 0,97\%. Ao que a investigação permite afirmar, os municípios estudados em que a rede de assistência à saúde é mais bem constituída propiciaram não apenas o atendimento, mas também a visibilidade da quantidade de acidentes e sua notificação. O regime de tratamento, como é possível visualizar na Tabela 12, foi ambulatorial em $61,27 \%$ dos casos; hospitalar em $28,82 \%$ e ambos em 3,79\%, corroborando com os achados de Scussiato et al. (2013) e Cardoso et al. (2016).

TABELA 13 - EVOLUÇÃO DOS CASOS

\begin{tabular}{|c|c|c|c|c|c|}
\hline \multirow{2}{*}{ Evolução do caso } & \multicolumn{4}{|c|}{ Regionais de Saúde } & \multirow{2}{*}{ Total } \\
\hline & Ponta Grossa & Irati & União da Vitória & Telêmaco Borba & \\
\hline $\begin{array}{l}\text { Incapacidade } \\
\text { temporária }\end{array}$ & 677 & 1356 & 468 & 402 & 2903 \\
\hline Cura & 196 & 664 & 790 & 270 & 1920 \\
\hline Ign./Branco & 127 & 21 & 172 & 304 & 624 \\
\hline Outra & 6 & 6 & 4 & 514 & 530 \\
\hline Óbito pelo acidente & 100 & 33 & 28 & 44 & 205 \\
\hline $\begin{array}{l}\text { Incapacidade parcial } \\
\text { permanente }\end{array}$ & 84 & 42 & 30 & 45 & 201 \\
\hline $\begin{array}{l}\text { Incapacidade total } \\
\text { permanente }\end{array}$ & 6 & 4 & 9 & 2 & 21 \\
\hline Óbito por outras causas & 2 & 0 & 1 & 1 & 4 \\
\hline Total & 1198 & 2126 & 1502 & 1582 & 6408 \\
\hline
\end{tabular}

Fonte: Relatório do SINAN 2009 a 2015, CEREST Campos Gerais-PR.

A evolução do caso gerou incapacidade temporária em 45,30\% dos trabalhadores e cura em $29,96 \%$. Os óbitos tiveram uma porcentagem relativamente baixa, sendo 3,20\% referente 
a óbitos pelo acidente e $0,06 \%$ por outras causas, dado que não deve ser desconsiderado. Tais informações também são obtidas por Scussiato et al. (2013), Cardoso et al. (2016), Cavalcante et al. (2015) e Campos e Gurgel (2016).

O ano com maior número de óbitos foi 2014, com 38 ocorrências, o segundo foi 2010, com 36, e o terceiro em 2015, com 34. É perceptível, a partir de 2010, o aumento no número de óbitos, o que pode estar relacionado também ao aumento no número de notificações.

TABELA 14 - ANOS DOS ÓBITOS

\begin{tabular}{|c|c|c|c|c|c|}
\hline \multirow{2}{*}{ Ano } & \multicolumn{4}{|c|}{ Regionais de Saúde } & \multirow{2}{*}{ Total } \\
\hline & Ponta Grossa & Irati & União da Vitória & Telêmaco Borba & \\
\hline Em branco & 1095 & 2094 & 1473 & 1537 & 6199 \\
\hline 2008 & 1 & 0 & 0 & 0 & 1 \\
\hline 2009 & 11 & 2 & 3 & 0 & 16 \\
\hline 2010 & 23 & 3 & 2 & 8 & 36 \\
\hline 2011 & 19 & 6 & 2 & 6 & 33 \\
\hline 2012 & 11 & 2 & 8 & 9 & 30 \\
\hline 2013 & 10 & 5 & 2 & 4 & 21 \\
\hline 2014 & 12 & 7 & 11 & 8 & 38 \\
\hline 2015 & 16 & 7 & 1 & 10 & 34 \\
\hline Total & 1198 & 2126 & 1502 & 1582 & 6408 \\
\hline
\end{tabular}

Fonte: Relatório do SINAN 2009 a 2015, CEREST Campos Gerais-PR.

\section{DISCUSSÃO}

As informações produzidas durante a pesquisa mostraram que os acidentados são na maioria homens, brancos, jovens e em idade produtiva, com baixa escolaridade e empregados de indústrias ou de empreendimentos agrícolas. Tais dados compõem uma série histórica valiosa para comparações com outros períodos, mas prioritariamente para a definição da atuação direta e premente nos setores produtivos de maior ocorrência de acidentes de trabalho. Porém, ao tomar como base o número total de 5.967 acidentes de trabalho com mutilações notificados, dividindo-os por sete anos (recorte temporal da pesquisa) e depois pelos 37 municípios (pertencentes ao território analisado), chega-se a um total de 23 acidentes para cada um deles, por ano. Fica evidente que o empenho dos profissionais da área é o de diminuição quase que total dos casos, contudo, tal cálculo, grosso modo, favorece dúvidas sobre subnotificações, haja vista a presença de importantes setores de alta periculosidade e potencialidade de acidentes de trabalho, como parques industriais, produção madeireira e agrícola de alguns municípios como Ponta Grossa, Telêmaco Borba, Irati, São Mateus do Sul, Mallet, União da Vitória, que juntos ultrapassam a marca de 550.000 habitantes.

Embora a PNSST e a RENAST tenham sido criadas para fomentar as notificações e a produção de políticas públicas e intervenções com vistas à melhoria das condições de trabalho, parecem ainda aquém do proposto na região em que o estudo foi realizado, havendo muito a ser implementado e desenvolvido. Isso remete à implantação concreta e efetiva da legislação, diante das especificidades e necessidades dos trabalhadores e de seu contexto social. 
Nessa direção, a implementação da RENAST é desafiadora e nem sempre anda a passos largos. Gomez, Vasconcellos e Machado (2018) apontam algumas dificuldades enfrentadas ainda hoje nos vários âmbitos da PNSST enquanto política pública do SUS. A primeira a ser citada se refere aos percalços que intrincam a municipalização das ações em Saúde do Trabalhador, fator que pôde ser observado no presente estudo, seja pelo número de notificações, seja pelas precárias condições de trabalho dos Agentes de vigilância em Saúde do Trabalhador, seja das interferências que sofrem da parte de grupos com interesses econômicos e políticopartidários para sua não efetivação de ações preventivas, fiscalizatórias ou punitivas junto às empregadoras. Os autores prosseguem abordando outra questão importante: a participação de entidades sindicais e de trabalhadores, seja na gestão de ações em Saúde do Trabalhador, seja no exercício do Controle Social - atribuição prevista pela Lei Orgânica da Saúde (BRASIL, 1990). A baixa adesão dos trabalhadores a esse papel que deveriam desempenhar, segundo os autores, pode ser vinculada à contínua precarização do trabalho, à retirada de direitos e à falta de atenção às necessidades desses trabalhadores por parte do Estado. Além disso, o campo da Saúde do Trabalhador, muitas vezes, é marcado por disputas de interesse, conflitos e preconceitos que tornam ainda mais difícil o trabalho de técnicos e demais profissionais atuantes na área (GOMEZ; VASCONCELLOS; MACHADO, 2018).

Dois temas muitos presentes, que surgiram no diálogo com os funcionários do CEREST Campos Gerais e perceptível nos dados, é a dificuldade de notificar e a incompletude dos dados, questões distintas, mas ambas decorrentes da dificuldade e/ou do desconhecimento dos funcionários da rede sentinela acerca da importância de notificar e preencher corretamente todos os campos da ficha, conforme discutido por Iwamoto et al., (2011); Gonçalves (2012) e Santana et al. (2013). Tais aspectos contribuem para o aumento da subnotificação, além de outras questões, como receio dos profissionais de saúde de serem responsabilizados judicialmente, questões monetárias (BASTOS-RAMOS; SANTANA; FERRITE, 2015) e até mesmo ameaças externas, conforme relato dos trabalhadores do CEREST.

A importância de notificar reside no fato de as notificações consistirem na principal fonte de informações para subsidiar as ações de Saúde do Trabalhador e diminuir a precariedade e a ocorrência dos acidentes (GONÇALVES, 2012), dado o impacto econômico, social e até mesmo o sofrimento psíquico que causa às vítimas e aos familiares (MIRANDA et al., 2012). Como citado, acidentes de trabalho geram mais gastos à saúde pública, seja em serviços de saúde, seja nos serviços da previdência social, daí decorre a importância de investir em estratégias de prevenção e promoção de saúde no trabalho em nível público, privado (a cargo das empresas) e individual (CARDOSO et al., 2016).

A inconsistência nos dados também é um problema bem visível em algumas tabelas. Por exemplo, na que demonstra os municípios de residência do acidentado, há uma incoerência no total de acidentes, em que se acusa 163 notificações a mais do que nas outras tabelas, assim como todas as regionais apresentam maior número de AT do que nos outros. Por isso, optou-se em apresentar a sistematização apenas quanto ao município de notificação e não de residência dos trabalhadores. Outras inconsistências são encontradas nas tabelas de ocupação e diagnóstico da lesão. Contudo, como ressaltado por Cavalcante et al. (2015), para que haja mudanças concretas em relação à inconsistência e incompletude dos dados, é necessário que os governos invistam na estruturação do CEREST e em toda a rede sentinela, para que consigam dar conta da grande demanda de vigilância em saúde.

O SINAN é um sistema que pode ajudar a identificar as condições de trabalho (MIRANDA et al., 2012) e dar visibilidade aos acidentes como um todo, pois abrange todos os trabalhadores e não somente aqueles atendidos pela previdência social (CAVALCANTE 
et al., 2015). As fichas de notificação, do mesmo modo, constituem um instrumento muito potente para identificar as causas dos acidentes de trabalho, mas ambos são pouco explorados, acabando por ser restritos e gerar poucas informações. É necessário fazer com que os dados produzidos cheguem até as pessoas, problema levantado pelos funcionários do CEREST durante a realização da visita para coletar os dados. Uma das hipóteses é a de que muitas vezes os trabalhadores da rede sentinela não estão cientes da importância da notificação atenta e integral porque não têm acesso aos dados sistematizados e analisados ou, ainda, por não conseguirem visualizar os efeitos que os dados dos agravos podem ter na saúde dos trabalhadores.

Todavia, é preciso saber, também, o que cada trabalhador sente, como percebe e nomeia o sofrimento, bem como o sentido que atribui a ele. Todas essas questões compõem um sistema complexo que perpassa a subjetividade das pessoas e que é atravessado pelas instituições, moldando formas de pensar, sentir e intervir sobre o sofrimento provocado pelos acidentes de trabalho. Nessa direção, é preciso avançar em pesquisa sobre os efeitos do AT sobre a saúde mental do trabalhador, sobre sua identificação com o trabalho, suas expectativas e organização da sua vida e de sua família, da participação social e recolocação profissional, por exemplo. Há urgência ainda de mensurar quali e quantitativamente os impactos dos ATs na renda familiar, comunitária e do município; nos gastos do SUS e do INSS, entre outros, considerando-se a ausência temporária ou definitiva dos acidentados do mundo do trabalho.

Além disso, é importante destacar a existência do trabalho infantil e de adolescentes que, aqui neste estudo, são indivíduos que sofreram acidente de trabalho. O número pode ser ainda maior se considerada a subnotificação. O trabalho precoce é, de certa maneira, justificado por valores culturais que tomam o trabalho como meio para dignificar o homem e afastá-lo da criminalidade, tendo assim aceitação social (TORRES et al., 2010) ou mesmo um indicador de que é um meio encontrado para auxiliar na renda familiar (LACERDA et al., 2014b). Além disso, acidentes de trabalho com crianças e adolescentes podem ser indicadores de que esse público está exposto a riscos, consequência da não aplicação das leis de proteção à infância e à juventude e também da baixa adesão por parte dos empregadores ao programa de jovens aprendizes, isto é, acrescenta-se aos riscos a que estão expostos o trabalho ilegal (LEITE; ROCHA; ALBERTO, 2019; MOTA; PIRES, 2019).

Tendo tudo isso em vista, a prática do controle social previsto pela Lei Orgânica da Saúde (BRASIL, 1990) é de extrema importância para prevenir e diminuir os riscos de acidente no trabalho, bem como a articulação entre os órgãos não só da saúde, mas entre os órgãos públicos como um todo, promovendo ações integradas por meio do diálogo intersetorial, visando à produção de políticas públicas voltadas para a promoção, prevenção e proteção da saúde dos trabalhadores (LACERDA et al., 2014b). Como ressaltado por Iwamoto et al. (2011), os acidentes de trabalho não ocorrem ao acaso e podem ser previstos e prevenidos. Cabe também a nós, enquanto sociedade, questionar a pequena preocupação dos gestores (públicos e privados) quanto à importância dessa área, bem como cobrar a criação e manutenção de condições de atuação, de recursos e de pessoal necessários para o bom andamento do SUS e do desenvolvimento das estratégias de Saúde do Trabalhador em especial.

\section{CONCLUSÕES}

O presente estudo identificou que ainda há a necessidade de melhorar as notificações de acidentes de trabalho e orientar seu correto preenchimento, para maior completude dos dados na região investigada. Ademais, também se faz necessário compreender melhor a relação entre os acidentes sofridos e seu nexo causal, bem como as questões sociais, raciais e econômicas 
que influenciam a prevalência de acidentes em determinado grupo social ou faixa etária em detrimento de outros. Nessa direção, trata-se de um estudo parcial, não generalizável, mas que guarda a potencialidade de subsidiar o manejo de ações públicas em saúde do trabalhador nos Campos Gerais, estado do Paraná.

É imprescindível que haja maior sensibilização, capacitações e condições de trabalho para que os profissionais da rede sentinela possam preencher corretamente todos os campos da ficha de notificação e também salientar a importância dos dados para as ações de políticas públicas. Ademais, faz-se importante investigar, junto aos trabalhadores de saúde, como eles percebem as fichas de notificação ou o ato de notificar, quais dificuldades encontram para isso e que sugestões apresentam para tornar viável e significativo o processo de conhecer o trabalhador e realizar a notificação do acidente de trabalho. Outras pesquisas poderiam buscar compreender o porquê se notifica tão pouco e porque há tantas subnotificações, assim como verificar possíveis meios para facilitar o preenchimento das fichas e a melhoria tecnológica do próprio SINAN e sua alimentação, entre outras questões.

A discussão sobre saúde do trabalhador e os acidentes de trabalho e sua prevenção deveriam ser de apropriação também da população, para que, ciente de seus direitos e da complexidade que envolve uma notificação e sua utilização no mundo do trabalho, possa se organizar em torno da construção e do aprimoramento conjunto de todo o sistema que envolve o registro de informações, mas, sobretudo, da fiscalização e exigência de efetivação de ações que visem reduzir as subnotificações e diminuir a precariedade e periculosidade no trabalho, tomando-se o sistema como uma das referências para isso.

Faz-se urgente, ainda, priorizar o olhar para cada acidente como produtor de sofrimento para um indivíduo que é singular, tem a própria maneira de pensar e significar as consequências do ocorrido e não o tratar como mais um número nas estatísticas. É preciso avançar nas tarefas de proteção ao trabalhador e trabalhadora, de promoção de bem-estar no/do trabalho e fora dele, tomando como premissa e compromisso que o trabalho seja mais facilitador e elemento constituinte de vida, saúde e emancipação dos seres humanos e menos de dor, tristeza e perdas.

\section{REFERÊNCIAS}

BASTOS-RAMOS, T. P.; SANTANA, V. S.; FERRITE, S. Estratégia Saúde da Família e notificações de acidente de trabalho, Brasil, 2007-2011. Epidemiol. Serv. Saúde [on-line], v. 24, n. 4, p. 641-650, 2015. Disponível em: https://www.scielo.br/pdf/ress/v24n4/2237-9622ress-24-04-00641.pdf. Acesso em: 29 out. 2020.

BRASIL. Constituição da República Federativa do Brasil. Brasília, DF: Senado Federal, 1988. Disponível em: http://www.planalto.gov.br/ccivil_03/constituicao/constituicaocompilado.htm. Acesso em: 20 fev. 2017.

BRASIL. Lei no 8069, de 13 de julho de 1990. Dispõe sobre o Estatuto da Criança e do Adolescente e dá outras providências. Brasília: DF, 1990a. Disponível em: http://www.planalto. gov.br/ccivil_03/leis/L8069.htm. Acesso em: 8 ago. 2017.

BRASIL. Lei $\mathbf{n}^{\circ} \mathbf{8 0 8 0 / 9 0}$, de 19 de setembro de 1990. Dispõe sobre as condições para a promoção, proteção e recuperação da saúde, a organização e o funcionamento dos serviços correspondentes e dá outras providências. Brasília: DF, 1990b. Disponível em: http://www. planalto.gov.br/ccivil_03/leis/L8080.htm. Acesso em: 18 jan. 2017. 
BRASIL. Lei ${ }^{\circ}$ 8123, de 24 de julho de 1991. Dispõe sobre os Planos de Benefícios da Previdência Social e dá outras providências. Brasília: DF, 1991. Disponível em: http://www. planalto.gov.br/ccivil_03/leis/L8213cons.htm. Acesso em: 29 jan. 2017.

BRASIL. Ministério da Saúde. Gabinete do Ministério. Portaria n 204, de 17 de fevereiro de 2016. Define a Lista Nacional de Notificação Compulsória de doenças, agravos e eventos de saúde pública nos serviços de saúde públicos e privados em todo o território nacional, nos termos do anexo, e dá outras providências. Brasília: DF, 2016a. Disponível em: http://www. saude.pr.gov.br/arquivos/File/portaria204_2016NotificacaoCompulsoria.pdf. Acesso em: 25 ago. 2017.

BRASIL. Ministério da Saúde. Gabinete do Ministério. Portaria $\mathbf{n}^{\circ}$ 205, de 17 de fevereiro de 2016. Define a lista nacional de doenças e agravos, na forma do anexo, a serem monitorados por meio da estratégia de vigilância em unidades sentinelas e suas diretrizes. Brasília: DF, 2016b. Disponível em: http://www.cerest.piracicaba.sp.gov.br/site/images/U_PT-MSGM-205_170216.pdf. Acesso em: 25 ago. 2017.

BRASIL. Ministério da Saúde. Gabinete do Ministério. Portaria $\mathbf{n}^{\circ} \mathbf{7 7 7}$, de 28 de abril de 2004. Dispõe sobre os procedimentos técnicos para a notificação compulsória de agravos à saúde do trabalhador em rede de serviços sentinela específica, no Sistema Único de Saúde SUS. Brasília: DF, 2004. Disponível em: http://bvsms.saude.gov.br/bvs/saudelegis/gm/2004/ prt0777_28_04_2004.html. Acesso em: 4 mai. 2016.

BRASIL. Ministério da Saúde. Gabinete do Ministério. Portaria no 1679, de 19 de setembro de 2002. Dispõe sobre a estruturação da rede nacional de atenção integral à saúde do trabalhador no SUS e dá outras providências. Brasília: DF, 2002. Disponível em: http://ftp.medicina.ufmg. br/osat/legislacao/Portaria_1679_12092014.pdf. Acesso em: 18 jan. 2017.

BRASIL. Ministério da Saúde. Gabinete do Ministério. Portaria $\mathbf{n}^{\circ} \mathbf{1 8 2 3}$, de 23 de agosto de 2012. Institui a Política Nacional de Saúde do Trabalhador e da Trabalhadora. Brasília: DF, 2012. Disponível em: http://bvsms.saude.gov.br/bvs/saudelegis/gm/2012/prt1823_23_08_2012.html. Acesso em: 3 mai. 2016.

BRASIL. Ministério da Saúde. Secretaria de Atenção à Saúde. Departamento de Ações Programáticas Estratégicas. Notificação de Acidentes do Trabalho Fatais, Graves e com Crianças e Adolescentes. Saúde do Trabalhador. Protocolos de Complexidade Diferenciada. Brasília: DF, 2006. Disponível em: http://bvsms.saude.gov.br/bvs/publicacoes/06_0442_M. pdf. Acesso em: 18 jan. 2017.

BRASIL. Ministério da Saúde. Secretaria de Vigilância em Saúde. Departamento de Vigilância Epidemiológica. Sistema de Informação de Agravos de Notificação (SINAN). Normas e rotinas. 2. ed. Brasília: DF, 2007. Disponível em: http://bvsms.saude.gov.br/bvs/ publicacoes/07_0098_M.pdf. Acesso em: 18 jan. 2017.

CAMPOS, A. G.; GURGEL, A. M. Acidentes de trabalho graves e atividades produtivas nas regiões administrativas de saúde em Pernambuco: uma análise a partir da identificação de aglomerados produtivos locais. Rev. Bras. Saúde Ocup., São Paulo, v. 15, n. 41, p.1-15, 2016. Disponível em: http://www.scielo.br/pdf/rbso/v41/2317-6369-rbso-41-e15.pdf. Acesso em: 19 jan. 2017.

CARDOSO, M. G. et al. Caracterização das ocorrências de acidentes de trabalho graves. Arq. Ciênc. Saúde, v. 23, n. 4, p. 83-88, 2016. Disponível em: http://www.cienciasdasaude.famerp. br/index.php/racs/article/view/502/243. Acesso em: 20 out. 2020. 
CAVAlCANTE, C. A. A. et al. Acidentes de trabalho grave no Rio Grande do Norte: estudo transversal. Online Brazilian Journal of Nursing, Rio de Janeiro, v. 14, n. 4, p. 543-555, 2015. Disponível em: https://www.redalyc.org/pdf/3614/361443264010.pdf. Acesso em: 28 out. 2020.

CFP - CONSELHO FEDERAL DE PSICOLOGIA. Saúde do Trabalhador no âmbito da Saúde Pública: referências para a atuação do(a) psicólogo(a). Brasília, DF: Conselho Federal de Psicologia/CREPOP, 2008.

DIAS, E. C.; HOEFEL, M. G. O desafio de implementar as ações de saúde do trabalhador no SUS: a estratégia da RENAST. Ciência \& Saúde Coletiva. Rio de Janeiro, v. 10, n. 4, p. 817-828, 2005. Disponível em: http://www.scielo.br/scielo.php?script=sci_ arttext\&pid=S1413-81232005000400007. Acesso em: 4 de mai. 2016.

GALDINO, A.; SANTANA, V. S.; FERRITE, S. Os Centros de Referência em Saúde do Trabalhador e a notificação de acidentes de trabalho no Brasil. Cad. Saúde Pública, Rio de Janeiro, v. 28, n. 1, p. 145-159, 2012. Disponível em: https://repositorio.ufba.br/ri/handle/ ri/5324. Acesso em: 19 jan. 2017.

GOMEZ, C. M.; VASCONCELlOS, L. C. F.; MACHADO, J. M. H. Saúde do trabalhador: aspectos históricos, avanços e desafios no Sistema Único de Saúde. Ciência \& Saúde Coletiva, v. 23, n. 6, p. 1963-1970, 2018.

GONÇALVES, K. R. Análise espacial dos acidentes de trabalho assentados no Sistema de Informação de Agravos de Notificação (SINAN) em uma capital brasileira. 2012. $194 \mathrm{f}$. Dissertação (Mestrado) - Escola de Enfermagem, Universidade Federal de Minas Gerais, Belo Horizonte, 2012. Disponível em: http:/www.enf.ufmg.br/pos/defesas/726M.PDF. Acesso em: 19 jan. 2017.

IBGE. Censo demográfico, 2010. Disponível em: http://www.ibge.gov.br/home/estatistica/ populacao/censo2010/default.shtm. Acesso em: 30 ago. 2017.

IWAMOTO, H. H. et al. Acidentes de trabalho fatais e a qualidade das informações de seus registros em Uberaba, em Minas Gerais e no Brasil, 1997 a 2006. Rev. Bras. Saúde Ocupacional, São Paulo, v. 36, n. 124, p. 208-215, 2011. Disponível em: https://fasul.edu.br/ portal/files/biblioteca_virtual/7/rbso124vol36.pdf\#page=24. Acesso em: 19 jan. 2017.

LACERDA, K. M.; FERNANDES, R. C. P.; NOBRE, L. C. C. Acidentes de trabalho fatais em Salvador, BA: descrevendo o evento subnotificado e sua relação com a violência urbana. Rev. Bras. Saúde Ocupacional, São Paulo, v. 39, n. 129, p. 63-74, 2014a. Disponível em: http:// www.scielo.br/scielo.php?script=sci_arttext\&pid=S0303-76572014000100063. Acesso em: 19 jan. 2017.

LACERDA, K. M. et al. A (in)visibilidade do acidente de trabalho fatal entre as causas externas: estudo qualitativo. Rev. Bras. Saúde Ocupacional, São Paulo, v. 39, n. 130, p. 127-135, 2014b. Disponível em: http://www.scielo.br/pdf/rbso/v39n130/0303-7657-rbso-39-130-127. pdf. Acesso em: 19 jan. 2017.

LEITE, L. L.; ROCHA, G. F.; ALBERTO, M. F. P. Acidentes de trabalho com crianças e adolescentes: dados conhecidos ou dados ocultados? Est. Inter. Psicol., Londrina, v. 10, n. 2, 2019. Disponível em: http://pepsic.bvsalud.org/scielo.php?script=sci_ arttext\&pid=S2236-64072019000200011. Acesso em: 20 out. 2020.

MINAYO, M. C. S. O desafio do conhecimento. 11 ed. São Paulo: Hucitec, 2008. 
MIRANDA, F. M. D. et al. Caracterização das vítimas e dos acidentes de trabalho fatais. Rev. Gaúcha Enfermagem, Porto Alegre v. 33, n. 2, p. 45-51, 2012. Disponível em: http://www. seer.ufrgs.br/RevistaGauchadeEnfermagem/article/view/22026. Acesso em: 19 jan. 2017.

MOTA, T. S.; PIRES, N. R. S. Trabalho precoce legal e ilegal no Brasil: uma análise sobre o perfil dos trabalhadores de 10 a 17 anos. In: ENCONTRO NACIONAL DE ESTUDOS POPULACIONAIS, 21., 2019, Poços de Caldas. Anais [...]. Poços de Caldas: ABEP, 2018. Disponível em: http://www.abep.org.br/publicacoes/index.php/anais/article/view/3127/2989. Acesso em: 20 out. 2020.

PARANÁ. Governo do Estado. Secretaria da Saúde. CEREST - Macrorregional Campos Gerais. Disponível em: http:/www.saude.pr.gov.br/modules/conteudo/conteudo. php?conteudo=2751. Acesso em: 30 ago. 2017.

POUPART, J. et al. A pesquisa qualitativa: enfoques epistemológicos e metodológicos. Trad. Ana Cristina Nasser. Petrópolis: Vozes, 2008.

RENAST - Rede Nacional de Atenção Integral à Saúde do Trabalhador. Manual de Gestão e Gerenciamento. 1. ed. São Paulo. 2006. Disponível em: http://bvsms.saude.gov.br/bvs/ publicacoes/ManualRenast06.pdf. Acesso em: 18 jan. 2017.

SANTANA, V. S., et al. Accidentes de trabajo fatales y violencia interpersonal en Brasil. 20002010. Salud Colectiva, Buenos Aires, v. 9, n. 2, p.139-149, 2013. Disponível em: http://www. scielosp.org/pdf/scol/v9n2/v9n2a02.pdf. Acesso em: 19 jan. 2017.

SCUSSIATO, L. A., et al. Análise dos agravos relacionados ao trabalho notificados pela unidade saúde do trabalhador. Rev. Min. Enfermagem, v. 14, n. 1, p. 88-95, 2010. Disponível em: http://pesquisa.bvsalud.org/enfermeria/resource/es/bde-18631. Acesso em: 19 jan. 2017.

SCUSSIATO, L. A., et al. Perfil epidemiológico dos acidentes de trabalho graves no Estado do Paraná, Brasil, 2007 a 2010. Epidemiol. Serv. Saúde, Brasília, v. 22, n. 4, p. 621-630, 2013. Disponível em: http://scielo.iec.pa.gov.br/pdf/ess/v22n4/v22n4a08.pdf. Acesso em: 19 jan. 2017.

TORRES, C. A. et al. Adolescência e trabalho: significados, dificuldades e repercussões na saúde. Interface - Comunic., Saúde, Educ., v. 14, n. 35, p. 839-50, 2010. Disponível em: http://www.scielosp.org/pdf/icse/v14n35/v14n35a10.pdf. Acesso em: 19 jan. 2017. 